\title{
WEAR BEHAVIOUR OF VANES FOR A ROTARY VANE EXPANDER WITH VARIOUS GRAPHITE MATERIALS UNDER DRY SLIDING CONDITIONS
}

\author{
Vaclav Vodicka*, Vaclav Novotny, Jakub Mascuch \\ Czech Technical University in Prague, University Centre for Energy Efficient Buildings, Trinecka 1024, \\ Bustehrad, 27343, Czech Republic \\ * corresponding author: vaclav.vodicka@cvut.cz
}

\begin{abstract}
This study presents tribological properties of various graphite materials of vanes for rotary vane expanders. A test device was developed in order to measure the wear and power dissipation under conditions similar to a real operation of a vane expander. Subsequently, the friction coefficients of vanes for a rotary vane expander were evaluated. Parameters of the test device are based on the vane expander used for an experimental organic Rankine cycle unit. Four materials in total were tested: graphite, antimony-impregnated graphite, 2D carbon fibre-reinforced graphite, and 2.5D carbon fibre-reinforced graphite. Wear tests were performed under dry sliding conditions at the temperature of $115^{\circ} \mathrm{C}$ and at $3030 \mathrm{rpm}$ for the total time of about 400 hours. The method of evaluating the wear involved measuring the vane weight loss in relation to the duration of the load. Furthermore, specific wear coefficients were established in order to evaluate the tribological properties of the tested materials. Measurements have shown that carbon fibre materials are the most advantageous in terms of wear. The best friction properties were obtained for the pure graphite.
\end{abstract}

KEYWORDS: vane; expander; carbon; fibre; graphite; composite; wear; friction; specific wear coefficient.

\section{INTRODUCTION}

Applications of organic Rankine cycle (ORC) systems are extending into smaller units, even into domesticsized ones. Volumetric expanders usually constitute an alternative to turbines in low power applications. Since scroll and screw expanders are too complex and expensive [1], vane expanders can be used due to their simplicity and low manufacturing costs. Therefore, vane expanders are also used in our experimental development of micro-ORC systems [2]. A description of a vane expander can be found, for example, in $[2,3]$. Vanes are the important components of rotary vane expanders. Their properties affect the overall efficiency and reliability of these expanders. One of the fundamental problems for a successful deployment of vane expanders is the durability of vanes. Studies related to friction and wear of vanes typically do not relate the wear of a material to the specific conditions of vane expanders. Usually, only the pin-on-disc wear test is performed. [4,5,6,7] However, working conditions of vanes in the expander within the ORC may differ considerably from the pin-on disc conditions. Therefore, a test device simulating the expander for determining the wear and friction behaviour of different types of materials was built. This device, as described later, allows performing multiple tests in order to assess the suitability of materials for vanes.

The first outcome of this work is the determination of the durability of vanes from different materials in order to estimate the appropriate time to replace worn vanes before they could cause a failure of the vane expander. However, wear resistance is not the only factor that affects the possibility of using the material for vanes within the vane expander. The second outcome deals with friction losses that negatively affect the overall efficiency of the expander; these should be as low as possible. It is desirable for the material of the vane to be light (lower centrifugal force) and to exhibit a low friction in combination with the stator cylinder. It is also necessary to use temperature-resistant materials with good mechanical properties. Therefore, we have focused on carbongraphite materials, which are light and tend to have a low friction coefficient in contact with other materials. It is also important that these graphite materials are highly resistant to chemicals in general so they seem suitable for the use in ORCs with any working fluid. The knowledge gained can be then applied to designing rotary vane expanders for ORC units or to the evaluation of their characteristics in order to optimize the effectiveness and costs of the whole device.

A research with similar objectives on friction losses of vanes within a sliding vane compressor was conducted by Murgia et al. [8] His work is focused on the experimental evaluation of the influence of two different materials of vanes (cast iron and aluminium with anodized surface) and four different lubricants on the overall mechanical power of the vane compressor. A detailed analysis of the forces acting on the vanes in vane compressors and of the friction losses was provided by Aradau [9] and later also by Bianchi and Cipollone [10, 11]. Bianchi and Cipollone also 


\begin{tabular}{lccc}
\hline Material & $\begin{array}{c}\text { Density } \\
{\left[\mathrm{kg} \mathrm{m}^{-3}\right]}\end{array}$ & $\begin{array}{c}\text { Flexural } \\
\text { strength [MPa] }\end{array}$ & $\begin{array}{c}\text { Compressive } \\
\text { strength [MPa] }\end{array}$ \\
\hline Graphite (KTI) & 1770 & 45 & 99 \\
Antimony-impregnated graphite (KTIU) & 2373 & 93 & 258 \\
2D carbon fibre-reinforced graphite (2D CFC) & 1480 & 170 & 100 \\
2.5D carbon fibre-reinforced graphite (2.5D CFC) & 1650 & 200 & 210 \\
\hline
\end{tabular}

TABLE 1. Tested materials for vanes
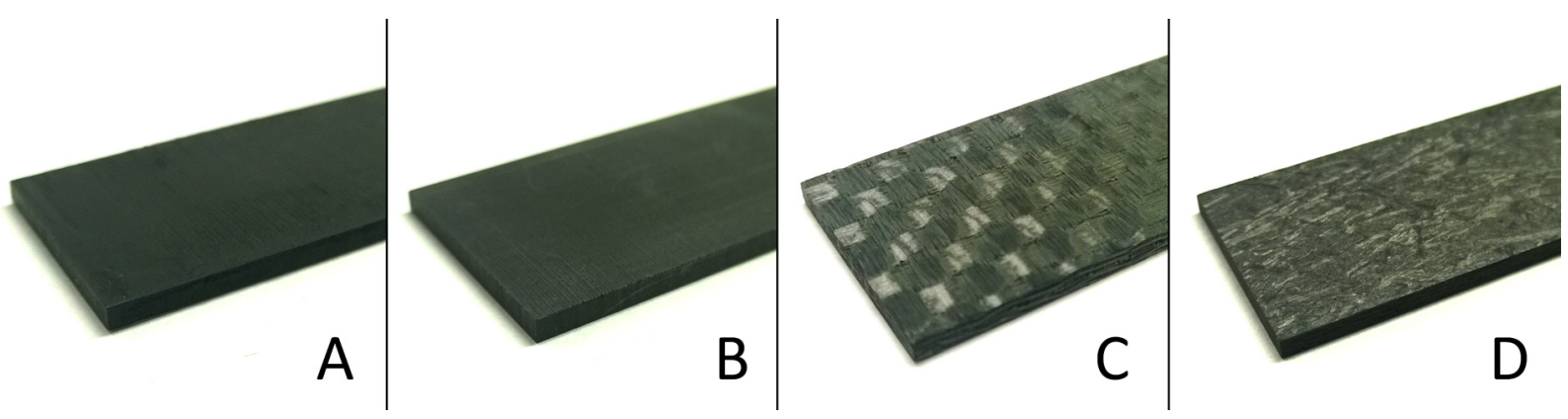

FiguRE 1. Tested materials: graphite (A), antimony-impregnated graphite (B), regular (2D) carbon fibre-reinforced graphite (C), irregular (2.5D) carbon fibre-reinforced graphite (D).
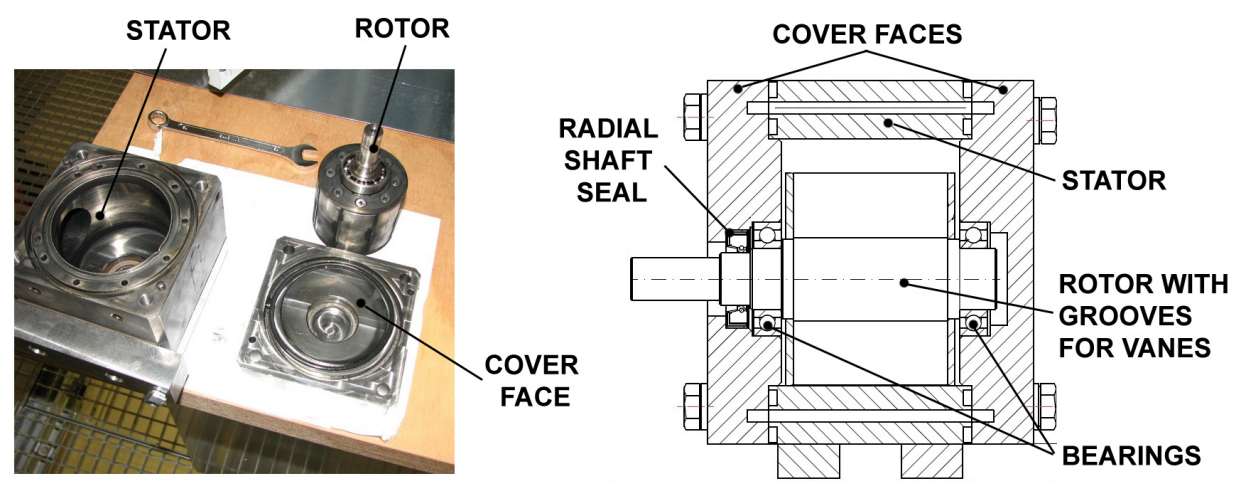

Figure 2. A photo (left) and a scheme (right) of the test device.

consider friction under the conditions of the hydrodynamic lubrication. Friction losses and the friction coefficient are determined indirectly by measuring the mechanical power of the compressor, the indicated power and the power for oil pressurizing. However, expanders have slightly different requirements on operating conditions and different types of materials are considered. As the amount of information on wear and friction of perspective graphite materials for expander vanes is very limited, we conducted the presented experimental analysis.

\section{Experimental PRocedure}

Four materials, which are shown in Tab. 1, were tested in total. The presented mechanical properties were taken from manufacturers' datasheets to show the differences between the tested materials, though their influence on wear and performance is not straightforward. The first material tested as a vane in the expander was graphite (KTI). Due to the possibly disadvantageous mechanical properties

\begin{tabular}{cccc}
\hline KTI $[\mathrm{g}]$ & KTIU $[\mathrm{g}]$ & 2D CFC $[\mathrm{g}]$ & $2.5 \mathrm{D} \mathrm{CFC}[\mathrm{g}]$ \\
\hline 3.43 & 4.76 & 2.92 & 3.25 \\
\hline
\end{tabular}

TABLE 2. Average weight of the tested vane.

of graphite, such as low flexural strength, other materials (antimony-impregnated graphite and graphite composites) have been tested. The advantage of the antimony-impregnated graphite (KTIU) should lie in better friction properties due to the added antimony. However, a disadvantage in power dissipation should be expected because this material has the highest density among the tested materials. The third tested material was the regular carbon fibre-reinforced graphite (2D CFC). In comparison with the other materials, it has a high flexural strength and also the lowest density. Lastly, the irregular carbon fibre-reinforced graphite (2.5D CFC) was tested. As shown in Tab. 1] it has the best values of flexural and compressive strength among the tested materials. 


\begin{tabular}{llcc}
\hline Sensor & Parameter & Range & Accuracy \\
\hline Torque and speed & torque $[\mathrm{Nm}]$ & $0-20$ & $0.2 \% \mathrm{f.s.}$ \\
sensor DR-2112R & speed [rpm] & $0-15000$ & $<0.2 \mathrm{rpm}$ \\
Pt100 sensor & temperature $\left[{ }^{\circ} \mathrm{C}\right]$ & $-50-+200$ & $0.30{ }^{\circ} \mathrm{C}+0.5 \%$ \\
Weighing scale DIA 20 & mass [g] & $0-10$ & $0.003 \mathrm{~g}$ \\
\hline
\end{tabular}

TABlE 3. Sensors that were used, along with their accuracy.

All the materials are shown in Fig. 1 1a-d. The difference between regular and irregular carbon fibrereinforced graphite is clearly visible from Figures 1c and $1 \mathrm{~d}$. While the regular carbon fibre-reinforced graphite has long, crossed fibres, the irregular carbon fibre has short, irregular fibres with a scattered placement.

The test device was designed to ensure that the working conditions of the vanes were similar to those in the actual vane expander. For this reason, the test device had the same dimensions as the vane expander used in the WHR ORC unit built and operated at the CTU UCEEB in Prague [2]. A photo and a scheme are shown in Fig. 2

The test device consists of a stator with an internal diameter of $80 \mathrm{~mm}$ and a rotor with a diameter of $69 \mathrm{~mm}$, which is mounted on bearings. The stator is covered by two faces. There are holes in the stator that simulate the inlet and outlet ports for the vapour inlet and outlet within the real expander. The surface of the stator cylinder is nitrided (hardness of 920-940 HV0.5) and it is ground to the roughness $\mathrm{Ra}=0.8 \mu \mathrm{m}$. The reason for the nitriding was to increase the abrasion resistance of carbon fibre materials, which, according to their manufacturer, can exhibit an abrasive behaviour.

To reduce the production costs, the length of the rotor $(50 \mathrm{~mm})$ is approximately one quarter $(50 \mathrm{~mm})$ as compared to the real expander. However, the linear dependence of the length of vanes and the friction losses can be assumed. There are 8 radial grooves in the rotor for vanes with dimensions of $50 \times 21 \times$ $2 \mathrm{~mm}$. The vanes started with sharp edges. Their tip curvature was developed quickly at the beginning of the operation due to the friction of the stator cylinder. It was also observed after the tests that the final radius of the tip was slightly smaller than the radius of the stator cylinder; this was caused by the eccentric placement of the rotor in the stator cylinder. All parts except for vanes are made of stainless steel. Tab. 2 shows the different average weight of vanes from the tested materials. The test device (expander model) was mounted to the aluminium frame (see Fig. 3).

The rotor shaft was coupled to a torque and speed sensor, which was then coupled to an asynchronous motor. Rotational speed was controlled by a variable frequency drive (VFD). An additional temperature sensor (Pt100) was used for measuring the temperature of the stator. The weight of the vanes was evaluated with an electronic weighing scale. All sen-

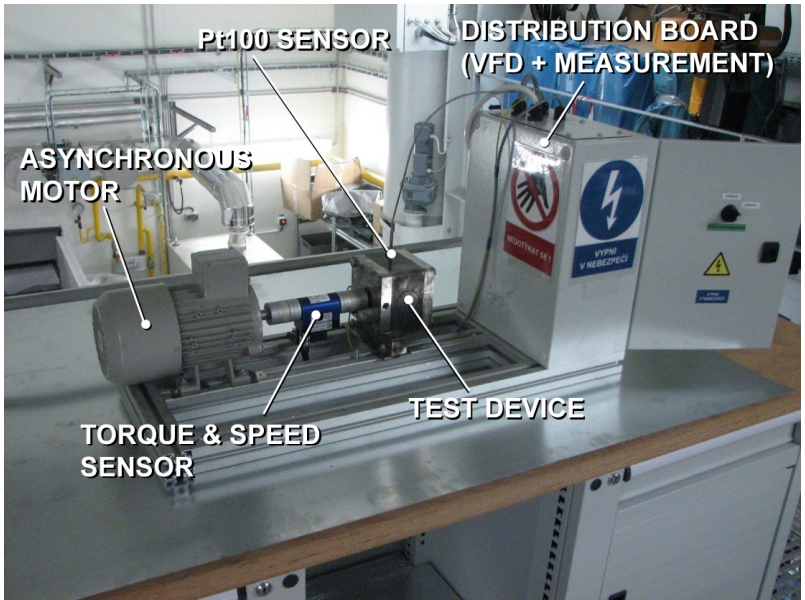

Figure 3. Test bench.

sors/devices used along with their accuracy are presented in Tab. 3 .

The expander, which these tests were performed for operates at $3030 \mathrm{rpm}$ and at a temperature between 150 and $190^{\circ} \mathrm{C}$. The temperature of the stator without insulation was stabilized at $(115 \pm 5){ }^{\circ} \mathrm{C}$ during the measurements of friction and wear. Increasing the temperature would be possible by insulating the stator. However, Luo et al. [13] observed that the wear rate of graphite against stainless steel increases rapidly between the room temperature and $100^{\circ} \mathrm{C}$ and only slightly between 100 and $200^{\circ} \mathrm{C}$. Therefore, it was sufficient to keep the stator uninsulated. The graphite dust from vanes was removed during tests through the holes in the stator. In a real ORC device, graphite dust and small parts of carbon fibres from the vanes can be trapped in the filter behind the pump (the position behind the pump is due to the pressure loss of the filter and to the prevention of cavitation). Otherwise, these very fine particles can circulate in the cycle and there is a risk of abrasion in the feed pump or in the expander. Clogging of conventional plate exchangers with these particles does not pose a threat.

All the tests of the graphite materials were carried out without a lubrication. Of course, dry conditions do not necessarily correspond to the working conditions of vane expanders. However, unlike compressors, it is more difficult for ORC systems to implement an oil circuit and the oil separation [12]. Therefore, it is common for the ORC with volumetric expanders that the oil is dissolved in the working fluid. The oil flow is several times smaller as compared to the case 


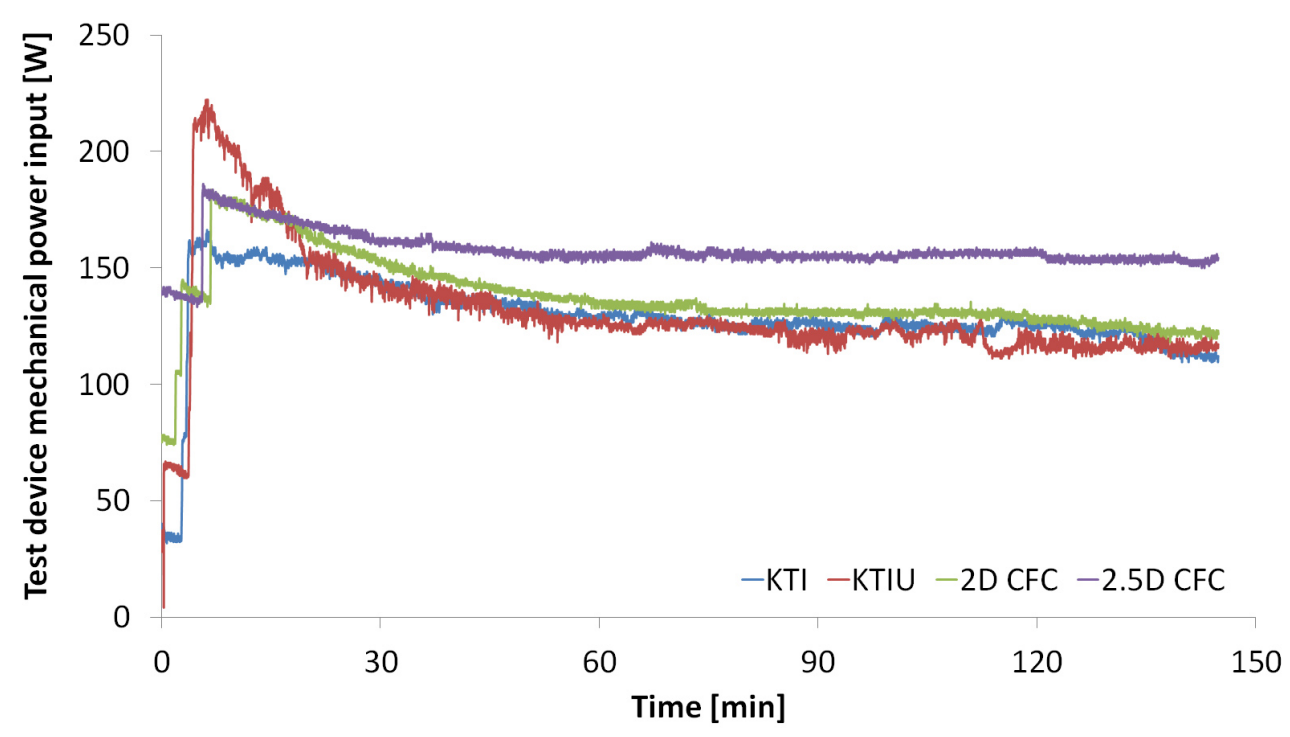

FiguRE 4. Example of the stabilization of friction conditions of vanes from different materials at $3030 \mathrm{rpm}$.

of separate injection of oil into the working chamber. The amount of oil so far may not be sufficient to create conditions for hydrodynamic lubrication of vanes in a real vane expander. Moreover, graphite materials are also suitable for running without any lubricants and could be used for vanes within a vane expander where the working substance or other circumstances exclude the possibility of lubrication. For wear tests, the percentage of oil that can be absorbed by the vanes would be uncertain as well; this would deteriorate the precision of the weight measurements.

Initially, measurements to determine the friction coefficient of the vanes from each material were performed. In order to evaluate the friction coefficient, an emphasis was put on stabilized friction conditions. The stabilization represents the adaptation of the roughness of the surface of the stator cylinder. J. Paolo Davim et al. [6] observed that different materials need different time for a surface adaptation. The time interval of 150 minutes was set; it represents the stabilization of the friction conditions between the vanes and the stator cylinder for all materials (see Fig. 4 as an example). The advantage of this interval is that uniform conditions for the evaluation of the friction coefficients are established.

The measurements were made with eight vanes made of each material. After the stabilization period, the frequency of the VFD was reduced to $30 \mathrm{~Hz}(\sim 1800 \mathrm{rpm})$ and gradually increased to $50 \mathrm{~Hz}$ $(\sim 3000 \mathrm{rpm})$ with a step of $5 \mathrm{~Hz}(\sim 300 \mathrm{rpm})$. The duration each setting of speed was retained for was approximately 1 minute; the data were logged every second. Average values were obtained from the measured speed and torque and the mechanical power input of the test device:

$$
\begin{gathered}
P_{\text {m,meas }}=\bar{T}_{\text {meas }} \bar{\omega}_{\text {meas }}[\mathrm{W}], \\
\bar{\omega}_{\text {meas }}=\frac{2 \pi \bar{N}_{\text {rot }, \text { meas }}}{60} \mathrm{rad} \mathrm{s}^{-1},
\end{gathered}
$$

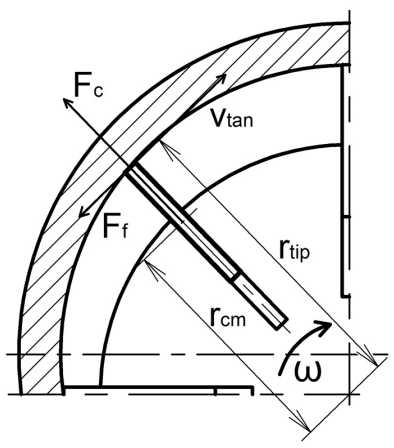

FiguRE 5. Simplified friction model: main forces acting on the vane.

which corresponds to the friction losses of bearings and vanes, was calculated. Note that the design of the test device does not allow the air to be compressed inside the device. In addition, the only loss is due to the ventilation inside the stator cylinder, which has a negligible significance.

For the evaluation of the vane friction coefficient, a simplified friction model was created. The simplified model (see Fig. 5) considers only the centrifugal force and neglects the friction in the slots for vanes, the Coriolis force $(C)$ and the force from relative acceleration $(K)$. The simplified model is based on the following:

$$
\begin{gathered}
P_{v}=F_{f} v_{t a n}=F_{c} \mu \omega \bar{r}_{v, t i p}[\mathrm{~W}], \\
F_{c}=m_{v} \omega^{2} \bar{r}_{c m}[\mathrm{~N}] .
\end{gathered}
$$

Due to the fact that the rotor is placed in the stator cylinder eccentrically, the distance between the centre of rotation and the centre of mass of a vane and its tip respectively varies depending on the angle of rotation of the rotor. However, the more detailed geometric analysis shows that when using the average radius values the error of the calculation is less than $0.2 \%$. 


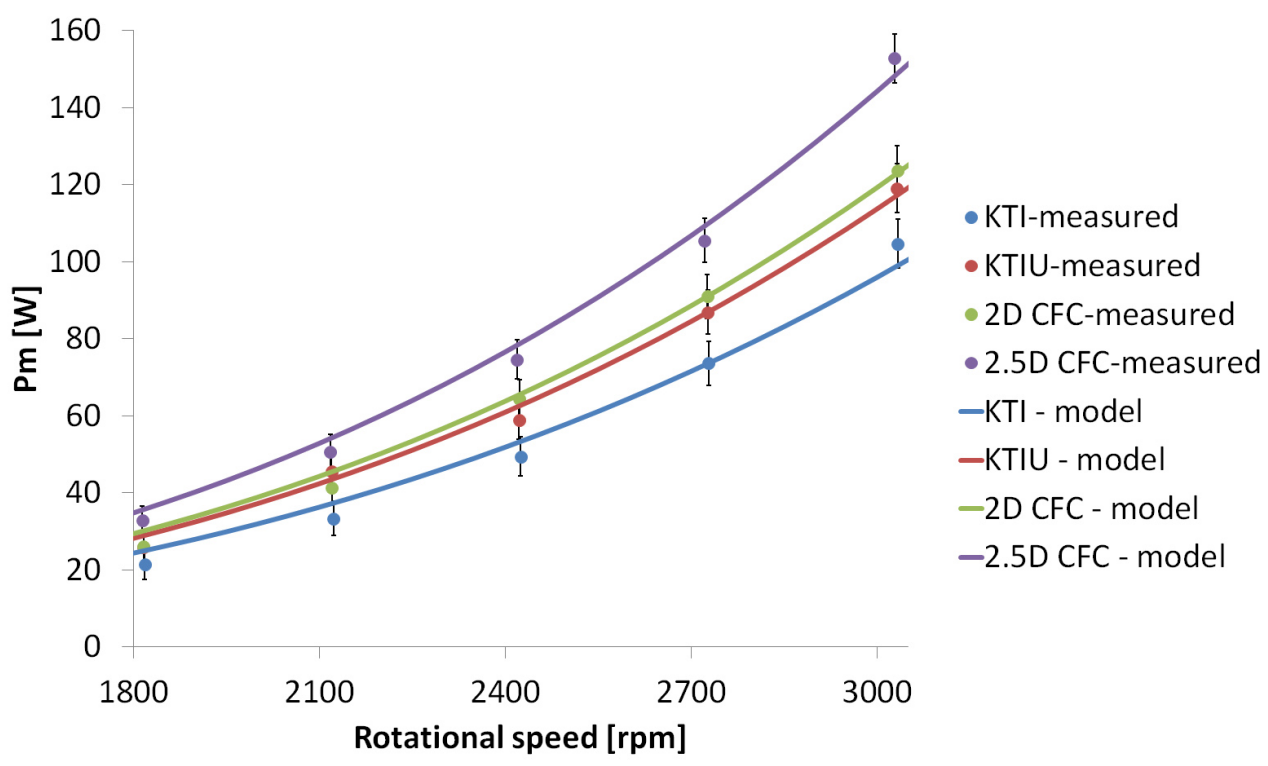

Figure 6. Measured mechanical loss and friction model for each material.

\begin{tabular}{lcccc}
\hline Material & $\mu[-]$ & $R^{2}[-]$ & $\mu \rho\left[\mathrm{kg} \mathrm{m}^{-3}\right]$ & $W_{s}\left[\mathrm{~mm}^{3} \mathrm{~N}^{-1} \mathrm{~m}^{-1}\right]$ \\
\hline Graphite (KTI) & 0.086 & 0.982 & 153 & $8.9 \cdot 10^{-7}$ \\
Antimony-impregnated graphite (KTIU) & 0.075 & 0.994 & 178 & $6.1 \cdot 10^{-7}$ \\
2D carbon fibre-reinforced graphite (2D CFC) & 0.128 & 0.994 & 190 & $3.7 \cdot 10^{-7}$ \\
2.5D carbon fibre-reinforced graphite (2.5D CFC) & 0.142 & 0.992 & 234 & $3.9 \cdot 10^{-7}$ \\
\hline
\end{tabular}

TABLE 4. Evaluated parameters of all tested materials.

When comparing the simplified model to the complete friction model presented by Aradau [9], the overall error of friction coefficient evaluation is below $1.5 \%$. Such a small error results from the fact that there is almost no pressure difference acting on the vane within this experimental device. Moreover, the radial speed of the vane in the rotor slot is almost ten times smaller than the tangential speed of the vane tip so the friction power dissipated between the vane side and the rotor slot is negligible. Thus, in this case, the simplified model can be used to evaluate the measured data with a sufficient accuracy.

Torque losses of the bearings were determined based on the torque measurements without vanes. Bearing losses can be then calculated:

$$
P_{b}=T_{b} \omega[\mathrm{W}]
$$

Once bearing losses have been determined, it is possible to calculate the friction coefficient $\mu$ based on the following:

$$
P_{m}=j P_{v}+P_{b}=j \mu m_{v} \omega^{3} \bar{r}_{c m} \bar{r}_{v, t i p}+P_{b}[\mathrm{~W}] .
$$

Note that the above equations also indicate that there is a cubic dependence of the friction loss of the vanes on the rotational speed and approximate quadratic dependence on the radius of the stator cylinder.

After carrying out the friction measurements, the wear tests were carried out. The goal of the wear measurements is to develop a function of wear (material loss) with respect to time. The mass measurements of the vanes were conducted from the time interval of a few hours to the time interval of three days. For the long term testing, six intervals of about 24 hours, two intervals of about 48 hours and two intervals of about 72 hours were used ( 377 hours in total). The testing of the rotational speed was chosen according to nominal operating conditions of the expander, i.e., $3030 \mathrm{rpm}$ which means the total test sliding distance L of approximately $17000 \mathrm{~km}$. To be complete, these conditions correspond to $p v_{\text {mean }} \approx 1.4 \mathrm{MPa} \mathrm{ms}^{-1}$. With mass loss $\Delta m$, it is possible to plot the time progress of wear for each material. The weight of the vanes was measured ten times after each test interval in order to obtain its mean value with a negligible uncertainty. Specific wear coefficient Ws (the same as used, e.g., in [6]) was calculated for each material using

$$
\begin{gathered}
W_{s}=\frac{\Delta V}{\bar{F}_{c} L}=\frac{\Delta m}{\bar{F}_{c} L \rho_{v}} \cdot 10^{9}\left[\mathrm{~mm}^{3} \mathrm{~N}^{-1} \mathrm{~m}^{-1}\right] \\
L=2 \pi \bar{r}_{v, t i p} \frac{N_{r o t}}{60} \Delta t[\mathrm{~m}]
\end{gathered}
$$

The error of using the mean values of centrifugal force $F_{c}$ and vane tip radius $r_{v, t i p}$ is below $3.5 \%$.

\section{Results And Discussion}

The friction coefficient was determined for each material based on the simplified friction model and the 


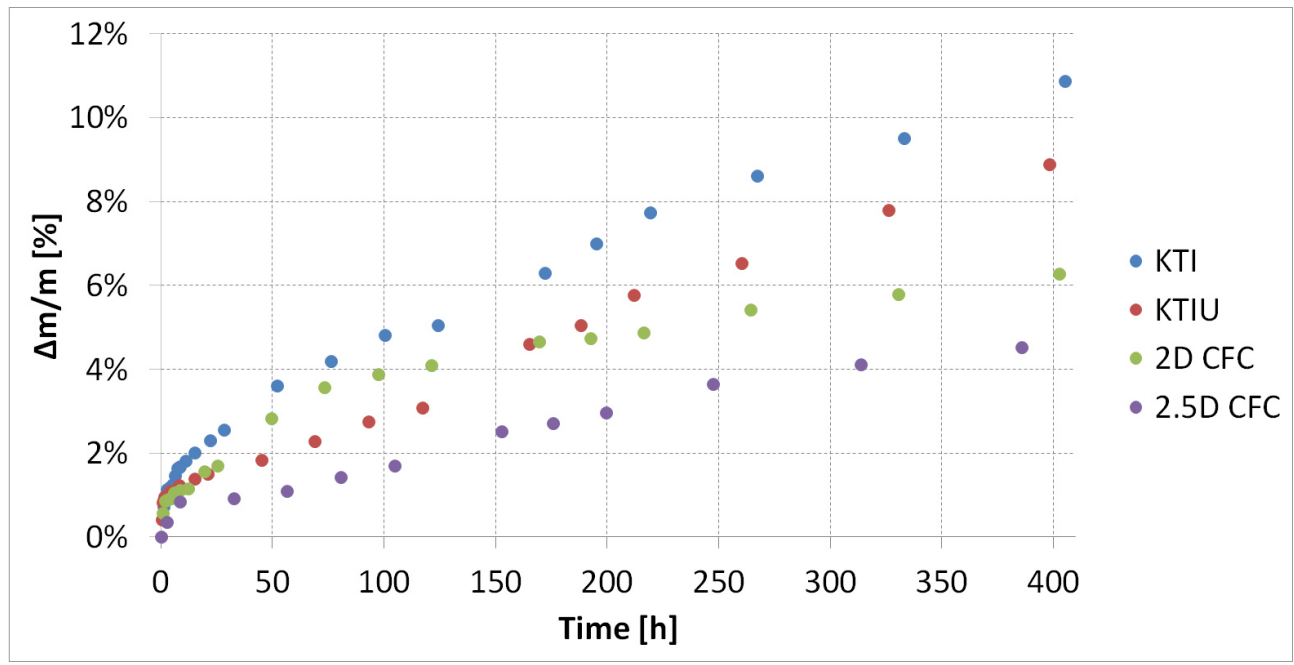

Figure 7. Cumulative weight loss of vanes.

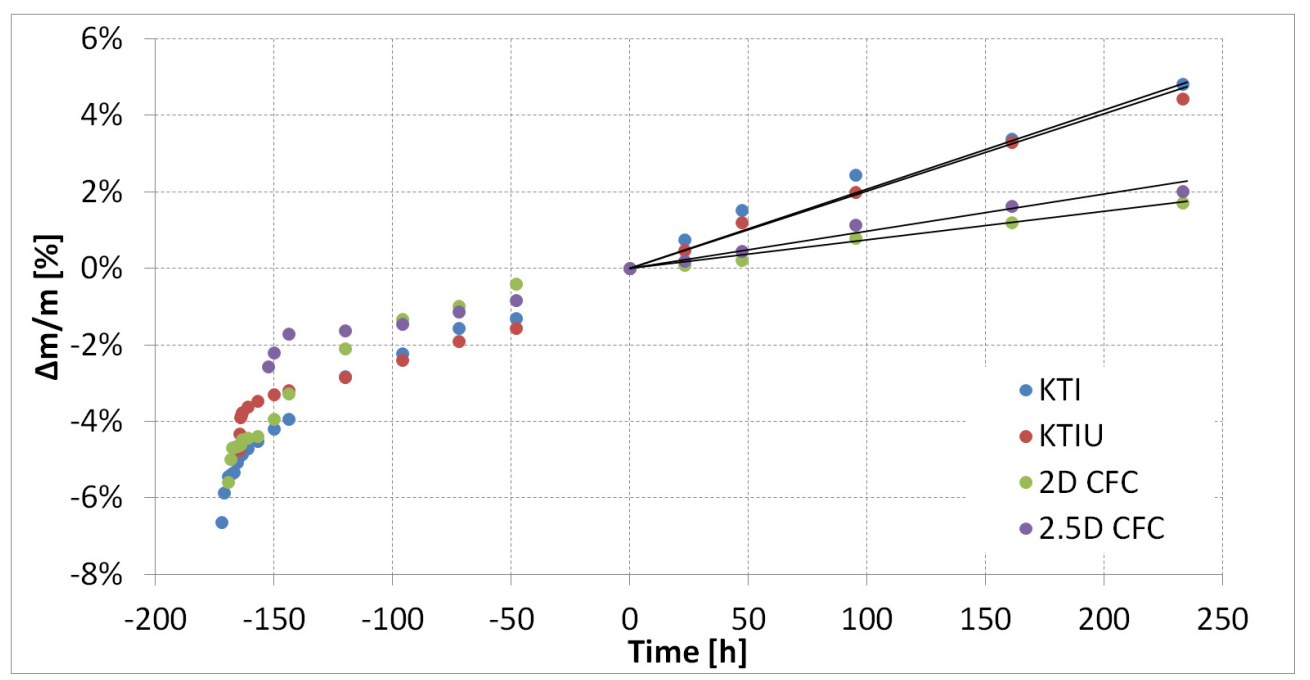

Figure 8. Cumulative weight loss of the vanes in the linear phase.

least squares method so that the performance predicted by the friction model matched the measured data. The resulting comparison of the measured data to the friction model and to the evaluated friction coefficient of each material is shown in the graph in Fig. 6. The 1-sigma uncertainty of measured data is also presented in the graph.

The resulting friction coefficients for each material together with coefficients of determination of $R^{2}$ of the friction model are shown in Tab. 4. The best sliding properties were found for the antimony-impregnated graphite, followed by the pure graphite. The largest, and still very low, friction coefficient was obtained for the irregular carbon fibre-reinforced graphite $-2.5 \mathrm{D}$ CFC. Based on (6), it is obvious that the resulting friction loss of the vanes depends on the product of the friction coefficient and the density of the vane material, since the volume of the vane is still the same. Thus, the product of the density of the material and the friction coefficient is given in Tab. 4. The lowest value indicates the most favourable material properties in terms of friction losses. From this perspective, the pure graphite appears to be the most advantageous one. The worst one is $2.5 \mathrm{D} \mathrm{CFC}$. The value of $\mu \rho$ is about $50 \%$ higher than in the case of the pure graphite. Note that the friction coefficient may not be constant and can vary slightly with the load. Therefore, the presented values are not valid universally.

The graph in Fig. 7] shows the measured cumulative weight loss of vanes from different materials over time.

It is obvious that the wear is high during the first dozens of hours. The weight loss is not constant and it decreases gradually. Moreover, each material behaves slightly differently in this stage and the duration of the initial stage is different for each material. This stage is followed by the stage in which the material wear is approximately constant and the cumulative weight loss is thus almost linear. For the evaluation of the specific wear coefficient $W_{s}$, the same time period was chosen for all materials; the wear of all materials was almost constant during this period. The time period can be seen in the graph in Fig. 8. It corresponds to approximately 230 hours of operation (distance of $10000 \mathrm{~km}$ ). The vanes reached this state 
in approximately 170 hours. The weight loss of the vanes is unified at the beginning of the graph and the linear character of the cumulative weight loss of all materials can be seen as well.

It is clear from the graph that when the vanes achieve the linear character of wear, the pure graphite and antimony-impregnated graphite show almost identical percentage weight loss. Carbon fibre-reinforced graphite composites exhibit considerably better characteristics in terms of wear. The difference between the 2D CFC and 2.5D CFC is marginal. Based on the measured data shown in Fig. 8 the specific wear coefficients Ws are summarized for each material in Tab. 4. This coefficient is related to the force acting on the material. However, this force is proportional to the weight of the vanes in the case of the vane expander and the test device. The specific wear coefficient $W_{s}$ of pure graphite is, therefore, about $45 \%$ higher as compared to the antimony-impregnated graphite, although their wear properties are similar in the conditions of the test device. In the linear phase of wear, the total wear $(\Delta m / m)$ after 230 hours was approximately $4.5 \%$ for the pure graphite and antimony-impregnated graphite and about $2 \%$ for the $2 \mathrm{D}$ CFC and 2.5D CFC. Carbon fibre-reinforced graphite composites are more suitable in terms of the lifetime of the vanes. Another significant reduction in wear or friction could be achieved by adjusting the surface of the stator cylinder of the expander in order to reduce its roughness, or by applying special coatings, such as WC/C (tungsten carbide/carbon) coating [14]. No wear of the stator cylinder was noticed after completing the experiments.

\section{Conclusion}

This paper deals with two main topics: friction losses and wear of vanes for rotary vane expanders for an ORC unit. An experimental device with the same geometry as a real vane expander was built to test wear and friction of vanes from various materials. Four different materials recommended on the basis of previous experience were tested in total. The following materials were tested during the experiment: graphite (KTI), antimony-impregnated graphite (KTIU), 2D carbon fibre-reinforced graphite (2D CFC), and 2.5D carbon fibre-reinforced graphite (2.5D CFC). The measurements were carried out with no additional lubricant, at the temperature of $115^{\circ} \mathrm{C}$, at the nominal speed of $3030 \mathrm{rpm}$ and with the length of the vane of $50 \mathrm{~mm}$.

Friction coefficient $\mu$ and specific wear coefficient Ws were determined for the investigated materials in order to identify the material with the most appropriate properties. The results of this study show that the addition of antimony to graphite has a very positive influence on the friction, and hence the friction coefficient of antimony-impregnated graphite reached the lowest values $\left(\mu_{K T I U}=0.075\right)$, followed by pure graphite $\left(\mu_{K T I}=0.086\right)$, regular carbon fibre $\left(\mu_{2 D C F C}=0.128\right)$ and irregular carbon fibre $\left(\mu_{2.5 D C F C}=0.142\right)$. Regarding the friction losses, the density of the material must be taken into account as well. In this case, pure graphite is the best one with $\mu \rho=153 \mathrm{~kg} \mathrm{~m}^{-3}$ while the $2.5 \mathrm{D} \mathrm{CFC}$ is the worst one with $\mu \rho=234 \mathrm{~kg} \mathrm{~m}^{-3}$.

The measurements showed that the materials with the lowest value of the specific wear coefficient were the $2 \mathrm{D} \mathrm{CFC}$ with $W_{s}=3.7 \cdot 10^{-7} \mathrm{~mm}^{3} \mathrm{~N}^{-1} \mathrm{~m}^{-1}$ and $2.5 \mathrm{D}$ CFC with $W_{s}=3.9 \cdot 10^{-7} \mathrm{~mm}^{3} \mathrm{~N}^{-1} \mathrm{~m}^{-1}$. The highest value of the specific wear coefficient was obtained for the pure graphite with $W s=8.9 \cdot 10^{-7} \mathrm{~mm}^{3} \mathrm{~N}^{-1} \mathrm{~m}^{-1}$. The total wear $(\Delta m / m)$ after 230 hours (distance of $10000 \mathrm{~km}$ ) was approximately $4.5 \%$ for the pure graphite and for antimony-impregnated graphite and about $2 \%$ for the $2 \mathrm{D} \mathrm{CFC}$ and for $2.5 \mathrm{D}$ CFC. The difference of the presented values can indicate up to a double lifetime of vanes from the carbon fibrereinforced graphite composites. However, when choosing the appropriate material for vanes, it is necessary to take the power dissipation of each material into account as well.

Another significant reduction in wear or friction could be achieved by adjusting the surface of the expander stator in order to reduce its roughness, or by applying special coatings, such as WC/C (tungsten carbide/carbon) coating.

\section{ACKNOWLEDGEMENTS}

This work has been supported by the Ministry of Education, Youth and Sports within the National Sustainability Programme I (NPU I), project no. LO1605 - University Centre for Energy Efficient Buildings - Sustainability Phase. The Authors are grateful to Mr. Tomas Kanovsky for his help throughout this research activity.

\section{LIST OF SYMBOLS}

$F$ Force [N]

$j$ Number of vanes $[-]$

$L$ Distance $[\mathrm{m}]$

$m$ Mass [kg]

$N_{\text {rot }}$ Rotational speed [rpm]

$P$ Power [W]

$r$ Radius [m]

$t$ Time [s]

$T$ Torque $[\mathrm{Nm}]$

$v$ Velocity $\left[\mathrm{m} \mathrm{s}^{-1}\right]$

$V$ Volume [m3]

$W_{s} \quad$ Specific wear coefficient $\left[\mathrm{mm}^{3} \mathrm{~N}^{-1} \mathrm{~m}^{-1}\right]$

$\Delta$ Difference

$\mu$ Friction coefficient [-]

$\rho$ Density $\left[\mathrm{kg} \mathrm{m}^{-3}\right]$

$\omega$ Angular velocity $\left[\mathrm{rad} \mathrm{s}^{-1}\right]$

b bearings

c centrifugal

$\mathrm{cm}$ centre of mass

$\mathrm{f}$ friction

$m$ mechanical

meas measured 


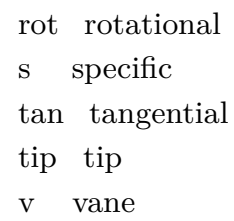

\section{REFERENCES}

[1] Gnutek, Z. and Kolasiński, P., 2013. The application of rotary vane expanders in organic Rankine cycle systems - thermodynamic description and experimental results. Journal of Engineering for Gas Turbines and Power, 135(6), p. 061901. DOI:10.1115/1.4023534

[2] Mascuch, J., Novotny, V., Vodicka, V. and Zeleny, Z., 2017. Towards development of $1-10 \mathrm{~kW}$ pilot ORC units operating with hexamethyldisiloxane and using rotary vane expander. Energy Procedia, 129, pp. 826-833. DOI:10.1016/j.egypro.2017.09.196

[3] Badr, O., O'Callaghan, P.W. and Probert, S.D., 1985. Multi-vane expanders: geometry and vane kinematics. Applied Energy, 19(3), pp. 159-182. DOI:10.1016/0306-2619(85)90006-6

[4] Jeon, H.G., Oh, S.D. and Lee, Y.Z., 2009. Friction and wear of the lubricated vane and roller materials in a carbon dioxide refrigerant. Wear, 267(5), pp. 1252-1256. DOI:10.1016/j.wear.2008.12.097

[5] Lee, Y.Z. and Oh, S.D., 2003. Friction and wear of the rotary compressor vane-roller surfaces for several sliding conditions. Wear, 255(7), pp. 1168-1173. DOI:10.1016/s0043-1648(03)00278-3

[6] Davim, J.P. and Cardoso, R., 2009. Effect of the reinforcement (carbon or glass fibres) on friction and wear behaviour of the PEEK against steel surface at long dry sliding. Wear, 266(7), pp. 795-799. DOI:10.1016/j.wear.2008.11.003

[7] Elliott, D.M., Fisher, J. and Clark, D.T., 1998. Effect of counterface surface roughness and its evolution on the wear and friction of PEEK and PEEK-bonded carbon fibre composites on stainless steel. Wear, 217(2), pp. 288-296. DOI:10.1016/s0043-1648(98)00148-3
[8] Murgia, S., Valenti, G., Contaldi, G. and Valenti, A., 2015. Experimental investigation on materials and lubricants for sliding-vane air compressors. In IOP Conference Series: Materials Science and Engineering (Vol. 90, No. 1, p. 012039). IOP Publishing. DOI:10.1088/1757-899X/90/1/012039

[9] Aradau, D. and Costiuc, L., 1996. Friction power in sliding vane type rotary compressors. International Compressor Engineering Conference, Paper 1357. DOI:10.1016/j.applthermaleng.2015.01.080

[10] Bianchi, G. and Cipollone, R., 2015. Theoretical modeling and experimental investigations for the improvement of the mechanical efficiency in sliding vane rotary compressors. Applied Energy, 142, pp. 95-107. DOI:10.1016/j.apenergy.2014.12.055

[11] Bianchi, G. and Cipollone, R., 2015. Friction power modeling and measurements in sliding vane rotary compressors. Applied Thermal Engineering, 84, pp. 276-285. DOI:10.1016/j.applthermaleng.2015.01.080

[12] Lei, B., Wu, Y.T., Wang, W., Wang, J.F. and Ma, C.F., 2014. A study on lubricant oil supply for positive-displacement expanders in small-scale organic Rankine cycles. Energy, 78, pp. 846-853. DOI:10.1016/j.energy.2014.10.079

[13] Luo, X., Yu, S., Sheng, X. and He, S., 2005. Temperature effect on IG-11 graphite wear performance. Nuclear Engineering and Design, 235(21), pp. 2261-2274. DOI:10.1016/j.nucengdes.2005.05.001

[14] Bloyce, A., 2000. Coatings for high performance pumps and compressors. World Pumps, 2000(400), pp. 43-45. DOI:10.1016/s0262-1762(00)89039-2 